\title{
Antioxidant activity of capsaicin on radiation- induced oxidation of murine hepatic mitochondrial membrane preparation
}

This article was published in the following Dove Press journal:

Research and Reports in Biochemistry

26 June 2015

Number of times this article has been viewed

\section{Ramachandran \\ Gangabhagirathi' \\ Ravi Joshi ${ }^{2}$}

'Bioorganic Division, ${ }^{2}$ Radiation and Photochemistry Division, Bhabha Atomic Research Center, Trombay, Mumbai, India
Correspondence: R Joshi Radiation and Photochemistry Division, Bhabha Atomic Research Center, Trombay, Mumbai 400085, India

$\mathrm{Tel}+912225590289 / 0415$

Fax +9| $222550515 \mid$

Email rjudrin@yahoo.com

\begin{abstract}
Capsaicin is the major capsaicinoid in chili peppers and is widely used as a spice. It is also used for topical applications in cases of peripheral neuropathy. The present study deals with its role in modulation of gamma radiation-induced damages of the biochemical constituents of rat liver mitochondrial membrane (RLM) preparation. The extent of lipid hydroperoxide formation, depletion in protein thiols, and formation of protein carbonyls have been biochemically assessed in the presence of varying concentrations of capsaicin in RLM. Decrease in the activities of the important antioxidant enzyme superoxide dismutase, which is involved in the scavenging of free radicals, and the mitochondrial marker enzyme succinate dehydrogenase have been also looked into. Capsaicin has been found to efficiently inhibit radiation-induced biochemical alterations, namely lipid peroxidation and protein oxidation. It also significantly prevented radiation-induced loss in the activity of antioxidant enzyme and the important endogenous antioxidant glutathione. The study suggests that capsaicin can act as an antioxidant and radioprotector in physiological systems.
\end{abstract}

Keywords: capsaicin, gamma radiation, radioprotection, lipid peroxidation, protein oxidation, enzyme activity

\section{Introduction}

Phenolic compounds are an important group of secondary metabolites, which are synthesized by plants in the process of the plant's adaptation to biotic and abiotic stress conditions. ${ }^{1,2}$ Taking a cue from nature, the same phenolic compounds present in food and medicines are also considered as powerful antioxidants. These compounds can protect the different biochemical components of the human body from oxidative stress conditions, producing highly reactive free radicals by scavenging them and inhibiting oxidative chain reactions. The natural metabolism of aerobic cells is associated with controlled formation of free radicals that are removed quickly and systematically by antioxidant defense system (enzymes and antioxidants). However, uncontrolled formation by exposure to ionizing radiation, chemicals, and disease conditions (inflammation, cancer, etc) can cause oxidative stress leading to damage and, ultimately, death of the cells. ${ }^{3,4}$ Many synthetic chemicals are known to inhibit oxidative damage to different extents, but they are also associated with unfavorable side effects. Therefore, investigation on free radical-scavenging aspects of antioxidant drugs made from natural food constituents has become not only very important but also essential due to their nontoxic nature, everyday intake through food, and favorable interaction with various free radicals in the living cells generated both from exogenous sources and in endogenous metabolic reactions..$^{5-7}$ 
In this context, capsaicin (trans-8-methyl- $N$-vanillyl-6nonenamide) present in chili fruits, which gives pungent flavor, is an important phenolic food constituent. Capsaicin (Figure 1) is present in several varieties of chili powders, with concentrations ranging from $\sim 0.3 \%$ to $\sim 2 \% \mathrm{wt} / \mathrm{wt}^{8}{ }^{8}$ In addition to being a food constituent, it is soluble in both aqueous $(\sim 40 \mu \mathrm{M})$ and lipid phase $(\log P=3.04)$, has low toxicity $\left(\mathrm{LD}_{50}\right.$ [median lethal dose $\left.] \geq 40 \mathrm{mg} / \mathrm{kg}\right)$, high stability $\left(p \mathrm{~K}_{\mathrm{a}}=9.75\right)$, and high bioavailability in different tissues which peaks at different times after oral administration $(\sim 3 \mu \mathrm{M}$ to $36 \mu \mathrm{M}){ }^{9-11}$

Capsaicin is reported to show a wide range of pharmacological properties, including antimutagenic, anticarcinogenic, ${ }^{12-15}$ and antioxidant activities, ${ }^{16-22}$ DNA protection against strand breaks and inhibition of chromosomal aberrations; ${ }^{23}$ protection of tissues against free radical-mediated damage induced by exogenous chemicals, ${ }^{24}$ inhibition of generation of reactive oxygen species; ${ }^{25}$ and induction of apoptosis. ${ }^{26,27}$

There are many studies using chemical, in vitro, and animal models indicating its strong antiradical activities. ${ }^{12-38}$ The peroxyl radical-scavenging ability of capsaicin is reported to be greater than that of both melatonin and caffeine. ${ }^{16,21}$ It was also shown to have antioxidant activity similar to that of flavonoids and $\alpha$-tocopherol. ${ }^{18,28}$ Further, capsaicin is also suggested to interact with xenobiotic metabolizing enzymes, for instance, microsomal P450-dependent monooxygenases. Capsaicin is assumed to convert to a phenoxyl radical intermediate through catalysis by hepatic cytochrome P450 2E1. This capsaicin phenoxyl radical is a highly reactive species and can chemically bind not only to the active site of the enzyme in a covalent manner but also with other biologically active macromolecules in the cells. It is proposed that suicidal inhibition of microsomal cytochrome P450 may prevent subsequent activation of chemical carcinogens, mutagens, and other toxic xenobiotics. Some studies indicate such chemopreventive roles of capsaicin against some of the chemical carcinogens and mutagens. ${ }^{12,39,40}$

It is known that free radicals produced during the natural metabolism of aerobic cells and stimulus (chemicals, ionizing radiation, etc)-induced oxidative stress can also be produced using gamma radiation. These free radicals react

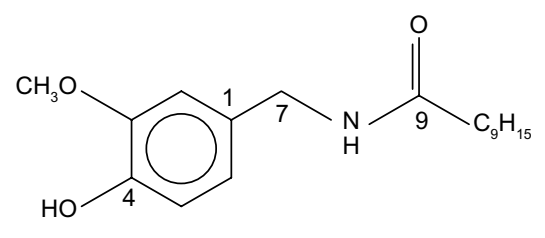

Figure I Structure of capsaicin. nonselectively with proteins, lipids, and others molecules in the vicinity due to their high reactivity and oxidize them to nonfunctional/deleterious products. In this context, the reported antiradical and antioxidant activity of capsaicin prompted us to investigate its protective effects against gamma radiation-induced oxidative damages in different components of mitochondrial preparation, namely, lipids, proteins, and enzymes. Mitochondrial preparation has been used as a model because it is the powerhouse of the cell, is involved in important electron transport event, and in the generation and breakdown of highly reactive oxygen species.

\section{Materials and methods Chemicals}

Capsaicin (trans-8-methyl- $N$-vanillyl-6-nonenamide) was procured from Sigma Chemicals (Perth, Australia). All other chemicals were of analytical grade. Solutions were prepared in Nanopure water from the Barnstead cartridge filtration system.

\section{Animals used}

Female Wistar rats (about 3-4 months old) housed in temperature- and humidity-controlled room $\left(24^{\circ} \mathrm{C} \pm 2^{\circ} \mathrm{C}\right)$ with a 12-hour light/dark cycle and fed the standard laboratory diet and water ad libitum were used. The guidelines issued by the Institutional Animal Ethics Committee of the Bhabha Atomic Research Centre, (Mumbai, India), regarding the maintenance and dissections of small animals were strictly followed.

\section{Mitochondria isolation from rat liver and irradiation}

Female Wistar rats ( $\sim 14$ weeks old) of about $250-300$ g have been used for the liver mitochondrial membrane preparation. The rats were sacrificed by cervical dislocation (without anesthesia) with due and proper permission and recommendation from the animal ethics committee. The liver was excised and homogenized in $0.25 \mathrm{M}$ cold sucrose containing $1 \mathrm{mM}$ EDTA, then centrifuged at $3,000 \times g$ for $10 \mathrm{~min}$, and the supernatant was centrifuged at $10,000 \times g$ for $10 \mathrm{~min}$ to sediment mitochondria. This pellet containing broken mitochondria was washed thrice with $5 \mathrm{mM}$ potassium phosphate buffer, $\mathrm{pH} 7.4$, to remove sucrose, and samples were maintained at $4{ }^{\circ} \mathrm{C}$ throughout. ${ }^{41}$ Lowry's ${ }^{42}$ method was used for protein estimation in the samples, $(10 \mathrm{mg} / \mathrm{mL})$ which were then stored for subsequent use.

Rat liver mitochondrial membrane (RLM) samples in the presence and absence of capsaicin were exposed to gamma $(\gamma)$ rays from a ${ }^{60} \mathrm{Co}$ source to cause radiation-induced 
oxidative damage. It is known that gamma radiation exposure causes damage to lipids and proteins, producing oxidized products such as lipid hydroperoxides, aldehydes, protein carbonyls, and oxidized thiol. The radiation-induced products of lipids and proteins were measured using different standard assays to understand the effect of capsaicin on the extent of damage and compared with the control set.

\section{TBARS assay}

Thiobarbituric acid reactive substances (TBARS) assay was performed by the standard method to measure malondialdehyde and other aldehydes, which are products of lipid peroxidation (LP). One aldehyde molecule condenses with two molecules of thiobarbituric acid (TBA) to produce a pink-colored species that absorbs at $532 \mathrm{~nm}$. The RLM were heated with TBA reagent (TBA-TCA-HCl-EDTA) for $20 \mathrm{~min}$ in a boiling water bath. The solution was cooled and then centrifuged, and the absorbance of supernatant was recorded at $532 \mathrm{~nm}^{43,44}$

\section{Lipid hydroperoxide}

Lipid hydroperoxides were estimated by the modified FOX (ferrous oxidation in xylenol orange) method ${ }^{45}$ Hydroperoxides oxidize $\mathrm{Fe}^{2+}$ to $\mathrm{Fe}^{3+}$ under acidic conditions, and xylenol orange (dye) complexes with an equal molar concentration of $\mathrm{Fe}^{3+}$ to produce a blue-purple colored complex with an apparent extinction coefficient of $1.5 \times 10^{4} \mathrm{M}^{-1} \mathrm{~cm}^{-1}$ at $560 \mathrm{~nm}$. FOX reagent consists of two solutions, solution A comprises of $98 \mathrm{mg}$ ammonium ferrous sulfate, $100 \mathrm{~mL} 250 \mathrm{mM} \mathrm{H}_{2} \mathrm{SO}_{4}$, and $79 \mathrm{mg}$ xylenol orange, and solution B comprises of $969 \mathrm{mg}$ butylated hydroxytoluene in $900 \mathrm{~mL}$ methanol, mixed in 1:9 ratio (stored in dark). About $875 \mu \mathrm{L}$ of FOX reagent was added to $125 \mu \mathrm{L}$ of the reaction mixture and incubated at $37^{\circ} \mathrm{C}$ for $30 \mathrm{~min}$. It was centrifuged at $10,000 \times \mathrm{g}$ for $15 \mathrm{~min}$ at $20^{\circ} \mathrm{C}$, and the absorbance was measured at $560 \mathrm{~nm}$.

\section{Protein thiol}

In this assay, RLM was suspended in 14\% perchloric acid, centrifuged at 4,500 $\times g$ for $5 \mathrm{~min}$, and the pellet was suspended in $7 \%$ perchloric acid and again centrifuged at $4,500 \times g$ for $5 \mathrm{~min}$. To the pellet were added, 10\% Triton X-100, $0.2 \mathrm{M}$ potassium phosphate buffer ( $\mathrm{pH}$ 7.4). Subsequently, addi-

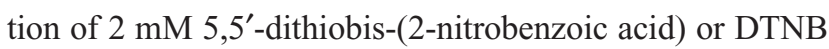
in the buffer was followed by measurement of absorbance at $412 \mathrm{~nm}$ after incubation for $5 \mathrm{~min}$ in the dark. ${ }^{46,47}$

\section{Protein carbonyl assay}

This assay involves the reaction of carbonyl groups with 2,4dinitrophenylhydrazine (DNPH) to form a 2,4-dinitrophe- nylhydrazone, which was estimated spectrophotometrically at $366 \mathrm{~nm}$. The experimental tubes and the corresponding blank set of tubes were treated with $20 \%$ TCA, vortexed, chilled on ice, and followed by centrifugation at 2,000 rpm for $20 \mathrm{~min}$. The pellets in the blank set of tubes were treated with $2 \mathrm{~mL}$ of $2 \mathrm{~N} \mathrm{HCl}$, whereas the pellets in experimental tubes were treated with $2 \mathrm{~mL}$ of $10 \mathrm{mM}$ DNPH in $2 \mathrm{~N} \mathrm{HCl}$. All the tubes were incubated at room temperature for $1 \mathrm{~h}$ followed by addition of $20 \%$ TCA to the tubes. The contents of the tubes were precipitated as pellets, washed thrice with a mixture of ethanol and ethyl acetate $(1: 1)$ to remove excess $\mathrm{DNPH}$, and then the pellets were dried and dissolved in $6 \mathrm{M}$ guanidine hydrochloride at $37^{\circ} \mathrm{C}$ for $20 \mathrm{~min}$. The absorbance was read at $366 \mathrm{~nm}$. The amount of carbonyls formed was calculated from the difference in absorbance between the blank and the corresponding experiment tube. ${ }^{48}$

\section{Superoxide dismutase}

The epinephrine method was used for superoxide dismutase (SOD) measurement. One $\mathrm{mL}$ of reaction mixture contained $50 \mathrm{mM}$ sodium carbonate buffer ( $\mathrm{pH} 10.0), 25 \mu \mathrm{L}$ of $20 \mathrm{mM}$ epinephrine in $0.1 \mathrm{~N} \mathrm{HCl}$, and about $20 \mu \mathrm{g}$ of protein in the enzyme sample. In the blank cuvette, the same amount of enzyme and buffer were taken, except epinephrine. Absorbance was recorded at $320 \mathrm{~nm}$ for $6 \mathrm{~min}$. The activity was calculated using the difference between absorbance of standard and absorbance of enzyme and is expressed as units/mg protein. ${ }^{49}$

\section{Succinate dehydrogenase}

Succinate dehydrogenase $(\mathrm{SDH})$ possesses dye reductase properties and is the only membrane bound enzyme in citric acid cycle. Phenazine methosulphate and 2,6-dichlorophenolindophenol are electron acceptor dyes in the assay. ${ }^{50}$ In this assay, the reaction mixture containing RLM is mixed with 0.1 M potassium phosphate buffer ( $\mathrm{pH} 7.4$ ) and $0.1 \mathrm{M}$ sodium cyanide and incubated at $37^{\circ} \mathrm{C}$ for $10 \mathrm{~min}$. Sodium cyanide completely inhibits oxygen consumption in respiring cells and thus fairly prevents the loss of succinate by oxidation. The contents were split into two cuvettes followed by the addition of $2 \mathrm{mM}$ phenazine methosulphate and $50 \mu \mathrm{M}$ 2,6-dichlorophenolindophenol. Addition of $50 \mu \mathrm{L}$ of $0.4 \mathrm{M}$ succinate to the experimental cuvette marks the start of the reaction, whereas $50 \mu \mathrm{L}$ of deionized water was added in the blank cuvette. Absorbance was recorded at $600 \mathrm{~nm}$ for $6 \mathrm{~min}$. SOD concentration is given in terms of "units", where one unit SOD causes $50 \%$ inhibition of auto-oxidation of epinephrine. 


\section{Total reduced glutathione (GSH) assay}

About $60 \mu \mathrm{L}$ of $O$-phosphoric acid was added to RLM and centrifuged. The supernatant was then mixed with $0.1 \mathrm{M}$ sodium phosphate buffer, $0.05 \mathrm{M}$ EDTA ( $\mathrm{pH} 8.0$ ), and $100 \mu \mathrm{L} O$-phthaldehyde $(1 \mathrm{mg} / \mathrm{mL})$ and incubated at room temperature for $15 \mathrm{~min}$ to measure GSH levels. Fluorescence was then recorded using an excitation wavelength of $350 \mathrm{~nm}$ and an emission wavelength of $420 \mathrm{~nm} . .^{51,52}$

\section{Statistical analysis}

The statistical significance of the difference in the parameters between the capsaicin-containing samples and the corresponding controls was tested. The measured values in different assays from six sets of experiments are reported as mean \pm standard error of mean. Analysis of variance was performed using "Origin6.1-Scientific Graphing and Data Analysis Software". The level of statistical significance $P<0.05$ is shown as * in Figures 2-5.

\section{Pulse radiolysis}

Electron beam irradiation with $7 \mathrm{MeV}$ pulses of $100 \mathrm{~ns}$ duration was used in the present work for in situ generation and study of transient species that was described earlier. ${ }^{53}$ Kinetics of the reactions were studied by observing formation or decay of the concerned transient's absorption with time at different concentrations of sample. ${ }^{54}$ Mechanism of reaction and kinetics of transients were studied by observing absorption at different wavelengths at different time points after irradiation.

\section{Results and discussion}

High-energy gamma radiation nonselectively deposits energy in the medium to produce oxidizing and reducing free radicals. Water-derived free radicals are produced in the physiological system on exposure to ionizing radiation since water is the major component. As the dose of radiation is increased, the extent of damage produced also increases and then reaches a plateau. Therefore, the radiation dose before the attainment of plateau has been chosen to study the influence of capsaicin on the radiation-induced oxidative damage. The effect of capsaicin has been investigated in terms of its ability to impart protection to isolated RLM preparation from gamma radiation-induced damages to lipids, proteins, antioxidant enzyme (SOD), and SDH.

In the present work, RLM has been used as an in vitro model of the biological system and not as a model of the living organism. The dose selected for the present study (450 Gy) produces $\sim 270 \mu \mathrm{M}$ (calculated) primary free radicals which can cause sufficient damage in the RLM to be measured conveniently and explicitly. The objective of the present study is to get radiation damage in the model system and not to mimic the conditions of cancer treatment. Further, capsaicin concentrations of up to $50 \mu \mathrm{m}$ have been used to study the protective effect of capsaicin against oxidative damage induced by $\sim 270 \mu \mathrm{M}$ primary free radicals. The effect of capsaicin on the studied parameters (without gamma irradiation) has been also shown in the figures.

Gamma radiation-induced damage to RLM components has been measured using standard assays. LP is defined as an oxidative deterioration of polyunsaturated fatty acids involving free radical-mediated chain reaction. Conjugated dienes, lipid hydroperoxides, aldehydes, and ketones are oxidation products of LP. These are reasonably stable molecules at physiological temperatures and can be estimated using different standardized assays. Capsaicin in the range of 5-25 $\mu \mathrm{M}$ imparted protection to RLM in terms of decrease in formation of radiation-induced TBARS and lipid hydroperoxides. Capsaicin has shown significant protection for lipids even at $5 \mu \mathrm{M}$ concentration, and this protection further increased linearly with concentration. Lipids (LH) are known to react with oxidizing hydroxyl radical $(\cdot \mathrm{OH})$ to produce carbon-centered radical by: 1) hydrogen atom abstraction, and 2) addition to unsaturation. These lipid radicals $(\mathrm{L} \cdot)$ react with oxygen to produce lipid peroxyl radical $\left(\mathrm{LO}_{2} \cdot\right)$, which initiates chain reaction causing lipid damage. The presence of capsaicin during irradiation significantly inhibited the formation of these lipid oxidation products in RLM (Figure 2A and B) in a concentration-dependent manner. The $\mathrm{IC}_{50}$ value has been found to be around 11.3 and $16.7 \mu \mathrm{M}$ for TBARS and $\mathrm{LOOH}$ (linoleic acid hydroperoxide) assays, respectively. We have also studied direct scavenging of $\mathrm{LO}_{2} \cdot$ with capsaicin, using pulse radiolysis technique. Capsaicin is known to react with oxidizing radicals to produce transient with absorption band at 380 $\mathrm{nm} .{ }^{55}$ High concentration of lipid (linoleic acid, $11.5 \mathrm{mM}$ ) has been reacted with hydroxyl radical $(8.4 \mu \mathrm{M})$ formed in situ in the presence of air $(0.25 \mathrm{mM}$ oxygen $)$ and low concentrations of capsaicin at $\mathrm{pH}$ 11. Capsaicin has been found to scavenge lipid peroxyl radical with a high bimolecular rate constant of $3.3 \times 10^{9} \mathrm{M}^{-1} \mathrm{~s}^{-1}$ (Figure 2C). This is a limiting value obtained with $0.11 \mathrm{mM}$ capsaicin due to 1) low absorption signal of capsaicin radical at $380 \mathrm{~nm}$ at lower concentrations and 2) saturation at higher capsaicin concentrations. The measured lipid peroxyl radical scavenging rate constant $\left(3.3 \times 10^{9} \mathrm{M}^{-1} \mathrm{~s}^{-1}\right)$ at $\mathrm{pH} 11$ is higher than that reported with $\mathrm{CCl}_{3} \mathrm{O}_{2} \cdot\left(2.0 \times 10^{9} \mathrm{M}^{-1} \mathrm{~s}^{-1}\right)$ and $\mathrm{CHCl}_{2} \mathrm{O}_{2}$. 

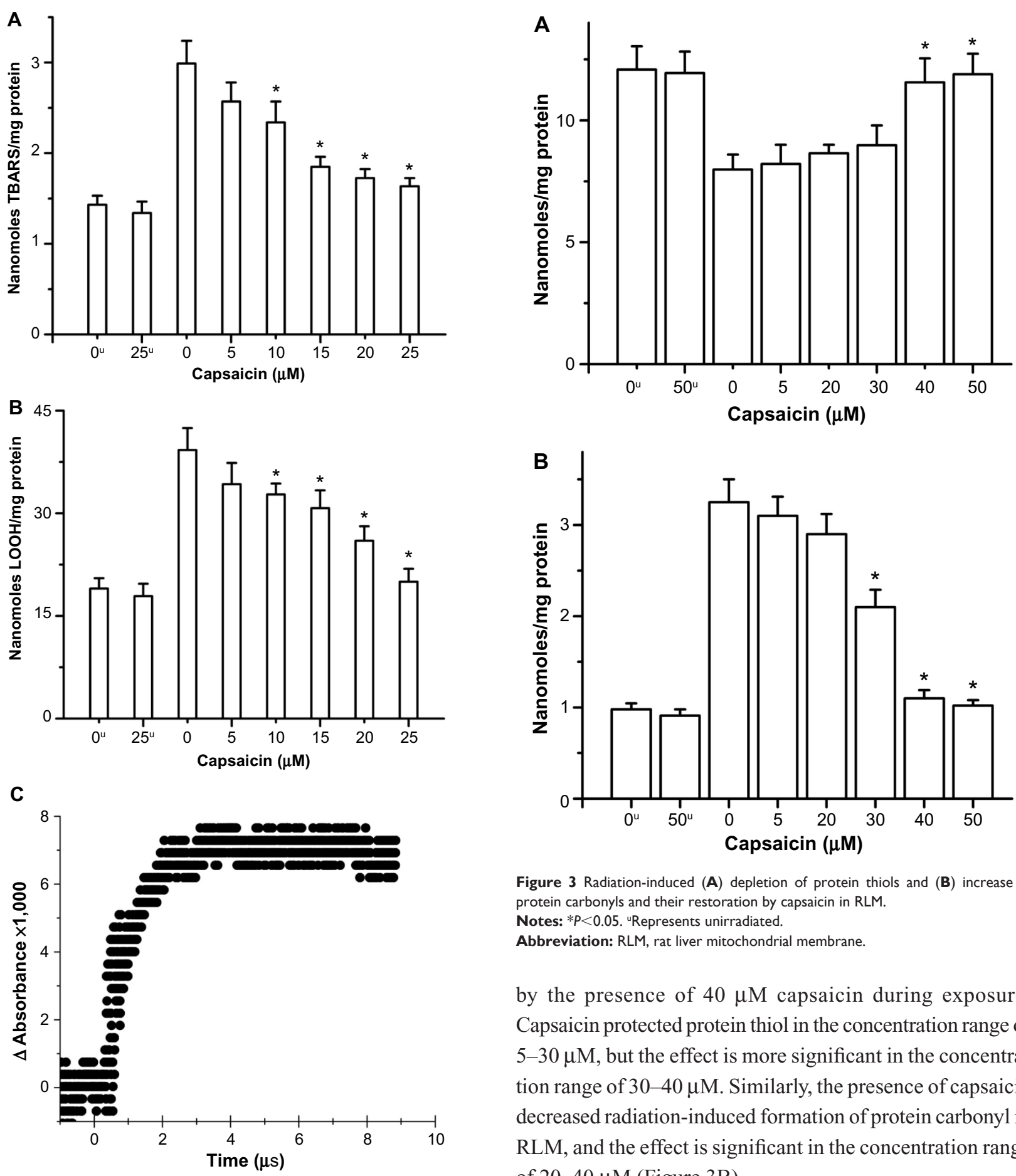

Figure 2 Radiation-induced increase in (A) TBARS and (B) lipid hydroperoxide and its restoration by capsaicin in RLM (C) lipid peroxyl radical scavenging by capsaicin. Notes: $* P<0.05$. "Represents unirradiated.

Abbreviations: TBARS, thiobarbituric acid reactive substances; $\mathrm{LOOH}$, linoleic acid hydroperoxide; RLM, rat liver mitochondrial membrane.

$\left(1.2 \times 10^{9} \mathrm{M}^{-1} \mathrm{~s}^{-1}\right)$ at $\mathrm{pH} 9.4 .{ }^{55}$ This agrees well with the fact that oxidation rate of any chemical increases significantly above its $p \mathrm{~K}_{\mathrm{a}}$ value (capsaicin $p \mathrm{~K}_{\mathrm{a}}=9.75$ ).

Gamma radiation-induced depletion of protein thiols in RLM has also been restored toward basal level (Figure 3A)

Figure 3 Radiation-induced (A) depletion of protein thiols and (B) increase in protein carbonyls and their restoration by capsaicin in RLM.

Notes: ${ }^{*} P<0.05$. "Represents unirradiated.

Abbreviation: RLM, rat liver mitochondrial membrane.

by the presence of $40 \mu \mathrm{M}$ capsaicin during exposure. Capsaicin protected protein thiol in the concentration range of 5-30 $\mu \mathrm{M}$, but the effect is more significant in the concentration range of $30-40 \mu \mathrm{M}$. Similarly, the presence of capsaicin decreased radiation-induced formation of protein carbonyl in RLM, and the effect is significant in the concentration range of 20-40 $\mu \mathrm{M}$ (Figure 3B).

Capsaicin also imparted protection to the antioxidant enzyme SOD from radiation-induced oxidative damage, which has been measured in terms of enzyme activity. The radioprotective action of capsaicin toward SOD has been found to be significant, even at $5 \mu \mathrm{M}$, and increased linearly from 5 to $25 \mu \mathrm{M}$ (Figure 4A). The presence of capsaicin also inhibited the gamma radiation-induced loss of activity of the mitochondrial marker enzyme $\mathrm{SDH}$, but it is significant only above $30 \mu \mathrm{M}$ concentration (Figure $4 \mathrm{~B}$ ). The protection 

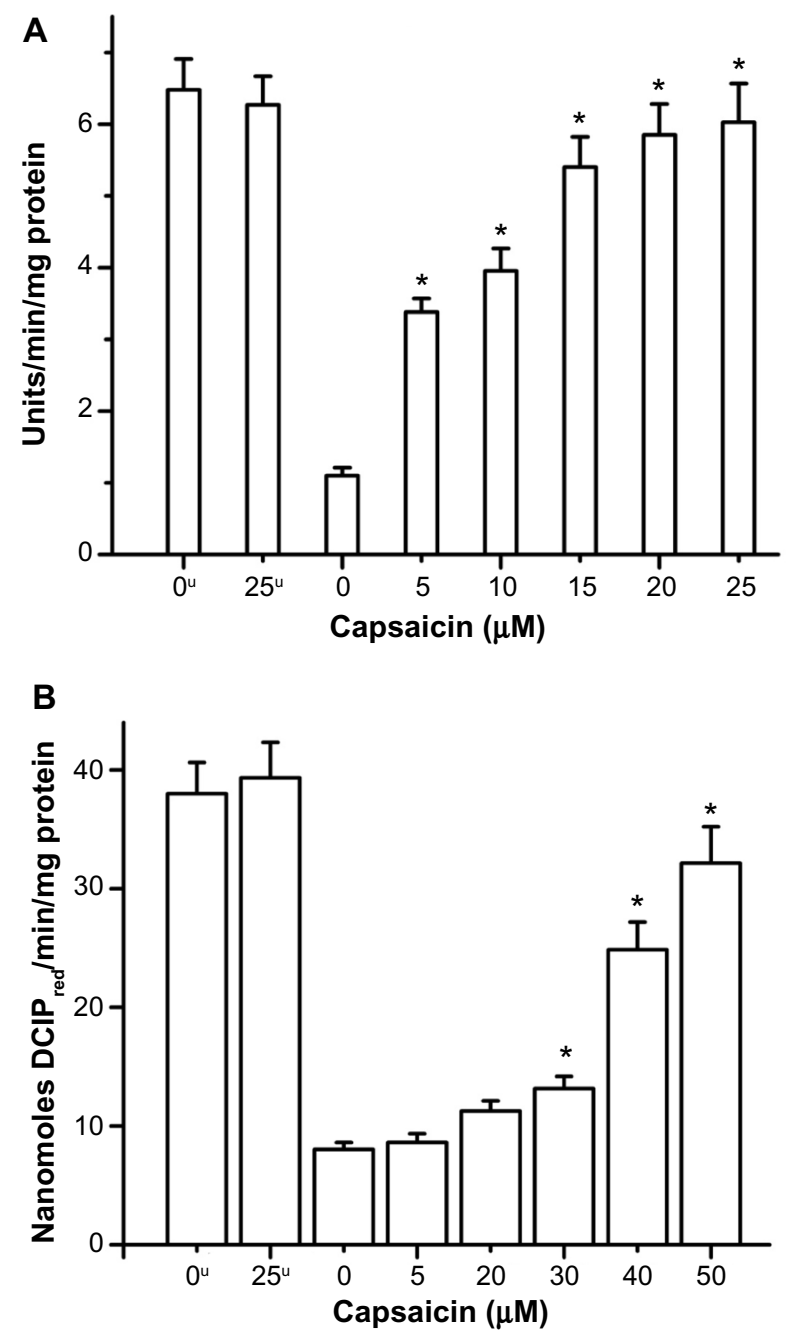

Figure 4 Radiation-induced decrease in activity of (A) SOD (superoxide dismutase) enzyme and (B) SDH (succinate dehydrogenase) enzyme and their restoration by capsaicin.

Notes: $* P<0.05$. "Represents unirradiated.

Abbreviation: DCIP, 2,6-dichlorophenolindophenol.

exerted by capsaicin against gamma radiation-induced loss of endogenous antioxidant GSH has been found even at $5 \mu \mathrm{M}$ concentration and increased almost linearly in the $5-25 \mu \mathrm{M}$ concentration range (Figure 5).

In the present study, capsaicin has shown protection against oxidative damages in the concentration range of 5-50 $\mu \mathrm{M}$. However, a particular concentration has not exerted the same level of protection against oxidative damages to different subcellular components. Therefore, a difference in capsaicin level has been observed to reverse the effect of gamma radiation for different components in RLM. This can be attributed to the octanol-water partition coefficient of capsaicin ( $\log P=3.04$ ), suggesting its high partitioning in lipid phase, which is reflected in terms of concentration dependent protection of lipids from 5 to $25 \mu \mathrm{M}$. Further, capsaicin completely inhibited LP process at $\sim 40 \mu \mathrm{M}$ concentration. It is

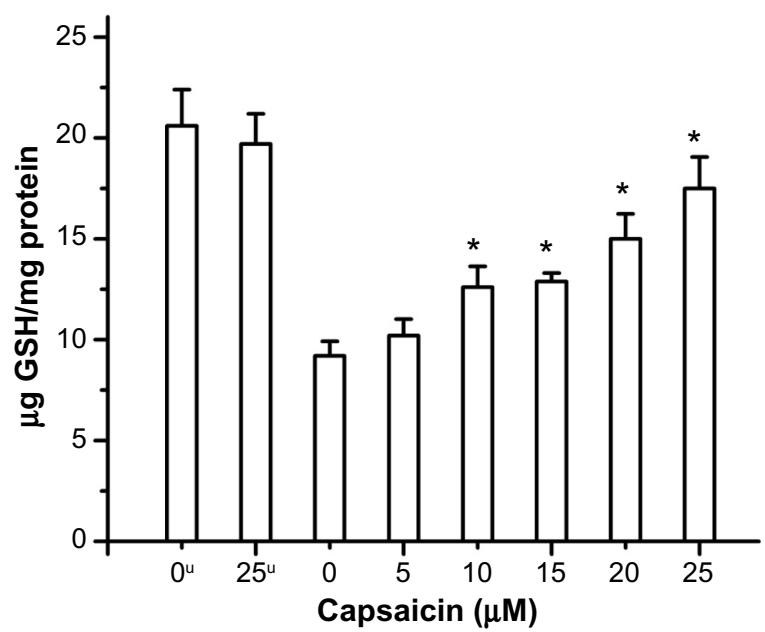

Figure 5 Radiation-induced depletion of GSH and its restoration by capsaicin. Notes: $* P<0.05$. "Represents unirradiated.

Abbreviation: GSH, glutathione.

to be noted that capsaicin inhibited protein thiol damage and protein carbonyl formation above $20 \mu \mathrm{M}$ and almost completely at $\sim 40 \mu \mathrm{M}$ concentration, which can be attributed to its solvation in some hydrophobic pockets of proteins/enzyme at lower concentrations. Moreover, radioprotection of GSH and SOD by capsaicin has been observed even at $5 \mu \mathrm{M}$ and is linear at higher concentrations.

Radiation-induced damage to proteins (including enzymes) can be studied directly by observing transients of amino acids produced in this process. Tyrosyl radical (TyrO, absorption maximum: $410 \mathrm{~nm}$ ) is one of the marker transient produced in the oxidative damage of proteins in addition to other transients. Therefore, scavenging of TyrO. with increasing concentration of capsaicin has been used as a model to study protection of proteins as exerted by capsaicin. An approximate value of TyrO radical scavenging by capsaicin could be measured due to overlap of transient absorption bands of capsaicin and tyrosine. Capsaicin $(28-115 \mu \mathrm{M})$ has been found to scavenge TyrO radical with a bimolecular rate constant of $1.2 \times 10^{7} \mathrm{M}^{-1} \mathrm{~s}^{-1}$.

The protection provided to protein thiol and GSH agrees well with our earlier report that capsaicin scavenges glutathiyl radical with a bimolecular rate constant of $3.4 \times 10^{9} \mathrm{M}^{-1} \mathrm{~s}^{-1} .{ }^{55}$ Our reported reduction potential value of capsaicin radical $(0.467 \mathrm{~V}$ vs NHE at $\mathrm{pH} 10.3)$ suggests that it can scavenge radicals of biomolecules, which agrees well with the radioprotection activity of capsaicin. ${ }^{55}$ The redox properties of capsaicin transients produced with hydroxyl radical can be studied by pulse radiolysis technique and redox standards, methyl viologen dication $\left(\mathrm{MV}^{2+}\right)$ and ABTS dianion $\left(\mathrm{ABTS}^{2-}\right) .{ }^{56,57}$ Methyl viologen is a well-known scavenger of electrons, with known redox potential $\left(E^{0}\left(\mathrm{MV}^{2+} / \mathrm{MV}^{+}\right)\right.$ 
$=-0.45 \mathrm{~V})$ and absorption maximum $(605 \mathrm{~nm})$. On the other hand, $\mathrm{ABTS}^{2-}$ anion is oxidized at $+0.68 \mathrm{~V}\left(\mathrm{ABTS}^{-}{ }^{-} / \mathrm{ABTS}^{2-}\right.$ ) to produce ABTS.- radical anion (absorption maximum at $650 \mathrm{~nm}$ ). Electron transfer from transient/s obtained in the reaction of capsaicin with $\cdot \mathrm{OH}$ radical to methyl viologen suggests that only $\sim 9 \%$ of them can reduce methyl viologen dication. Further, the capsaicin transients with $\cdot \mathrm{OH}$ radical have not been found to oxidize ABTS dianion. Moreover, capsaicin transients with $\cdot \mathrm{OH}$ radical are found to be rather unreactive toward reaction with oxygen.

As mentioned earlier, the formation of capsaicin phenoxyl radical in scavenging of oxidizing free radicals as well as by hepatic cytochrome P450 2E1 suggests an important role of both capsaicin and its phenoxyl radical in physiological systems. The mechanism of radioprotection by capsaicin in the present study seems to be primarily by way of scavenging of free radicals generated during exposure to gamma radiation in vitro. In an earlier study, incubation of DNA with a mixture of $\mathrm{FeSO}_{4}$ and $\mathrm{H}_{2} \mathrm{O}_{2}$ caused DNA strand scission, while addition of capsaicin to the incubation mixture decreased the strand scission in a concentration-dependent manner. ${ }^{58}$ Kinetic competition studies using 5,5-dimethyl-1-pyrroline $\mathrm{N}$-oxide indicated that the decrease in oxidative DNA damage was primarily because of scavenging of hydroxyl radical by capsaicin. ${ }^{58}$ Capsaicin has been shown to scavenge peroxyl radicals derived from $2,2^{\prime}$-azobis(2,4-dimethylvaleronitrile), as revealed by electron spin resonance spectroscopy ${ }^{58}$ Earlier studies on molecular mechanism of antioxidant activity of capsaicin are conflicting in nature. Those studies attribute either phenolic or C7-benzylic hydrogen in capsaicin to its antioxidant activities based on oxidation products of capsaicin. ${ }^{16,17}$ However, using pulse radiolysis technique, we have explicitly shown that capsaicin scavenges oxidizing free radicals, namely hydroxyl, azidyl, glutathiyl, and trichloromethylperoxyl radicals, to produce both phenoxyl and carbon-centered radical. ${ }^{55}$ The phenoxyl radical is known to dimerize through ortho-carbon atoms producing biphenolic dimers, as also reported for tyrosine. Moreover, the carboncentered benzylic radical can dimerize to produce biphenolic compound as reported earlier, using atmospheric pressure chemical ionization coupled mass spectroscopy study. ${ }^{16}$

The present study and literature suggest that radical scavenging activity of capsaicin plays a major role in protection of lipids ( $\mathrm{LH})$, proteins $(\mathrm{PH})$, and enzymes from gamma radiation-induced oxidative damage. Since hydroxyl radical is the most oxidizing radical produced in normal metabolism and ionizing radiation exposure, the reactions taking place in oxidative damage of the studied biomolecules and protection provided by capsaicin can be explained using it as a reactive radical [Equations (1)-(7)].

$$
\begin{aligned}
& \mathrm{LH}+\cdot \mathrm{OH} \rightarrow \mathrm{L} \cdot+\mathrm{H}_{2} \mathrm{O} \\
& \mathrm{L} \cdot+\mathrm{O}_{2} \rightarrow \mathrm{LO}_{2} \cdot \\
& \mathrm{LO}_{2}+\mathrm{LH} \rightarrow \mathrm{LO}_{2} \mathrm{H}+\mathrm{L} \cdot \\
& \mathrm{PH}+\mathrm{OH} \rightarrow \mathrm{P}(-\mathrm{CH} \cdot-)+\mathrm{H}_{2} \mathrm{O} \\
& \mathrm{P}(-\mathrm{CH} \cdot-)+\mathrm{O}_{2} \rightarrow \mathrm{P}(>\mathrm{C}=\mathrm{O}) \\
& \mathrm{L} \cdot / \mathrm{LO}_{2} \cdot / \mathrm{P}(-\mathrm{CH} \cdot-)+\text { Capsaicin } \\
& \quad \rightarrow \mathrm{LH} / \mathrm{LO}_{2} \mathrm{H} / \mathrm{PH}+\text { Capsaicin }(-\mathrm{H}) \cdot \\
& \text { Capsaicin }(-\mathrm{H}) \cdot+\mathrm{Capsaicin}(-\mathrm{H}) \cdot \\
& \quad \rightarrow \text { Capsaicin dimer/cleaved products }
\end{aligned}
$$

\section{Conclusion}

The present study indicates that capsaicin is an efficient antioxidant in the RLM model even at $5 \mu \mathrm{M}$. It is able to protect major biochemical components of the cells (lipids and proteins) from stress (radiation)-induced oxidative damage, and almost complete protection of lipids and proteins has been observed at $40 \mu \mathrm{M}$. Its other features like, natural occurrence and dietary component makes it attractive and suitable candidate as an antioxidant both in vitro and in vivo. Further, the ongoing studies with cell system may reveal the extent of protection exerted by capsaicin in in vivo systems.

\section{Disclosure}

The authors report no conflicts of interest in this work.

\section{References}

1. Shetty K. Role of proline-linked pentose phosphate pathway in biosynthesis of plant phenolics for functional food and environmental applications: a review. Process Biochem. 2004;39:789-803.

2. Pitchersky E, Gang DR. Genetics and biochemistry of secondary metabolites in plants: an evolutionary perspective. Trends Plant Sci. 2000;5:459-445.

3. Bors W, Heller W, Michel C, Stettmaier K. Flavonoids and polyphenols: chemistry and biology. In: Cadenas E, Packer L, editors. Handbook of Antioxidants. New York, NY: Marcel Dekker; 1996:409-466.

4. Halliwell B. Antioxidants in human health and disease. Annu Rev Nutr. 1996;16:39-50.

5. Halliwell B, Gutteridge JMC, editors. Free Radicals in Biology and Medicine. Oxford, UK: Oxford Press; 1999.

6. Sies H, editor. Antioxidants in Disease, Mechanisms and Therapy. New York, NY: Academic Press; 1997.

7. Thomas CE, Kalyanaraman B, editors. Oxygen Radicals and the Disease Process. Chur, Switzerland: Harwood Academic; 1999.

8. Musfiroh I, Mutakin M, Angelina T, Muchtaridi M. Capsaicin level of various capsicum fruits. Int J Pharm Pharm Sci. 2013;5:248-251.

9. Suresh D, Srinivasan K. Tissue distribution and elimination of capsaicin, piperine and curcumin following oral intake in rats. Indian J Med Res. 2010;131:682-691. 
10. Capsaicin [material safety data sheet]. TX, USA: Sciencelab. com, Inc. Available from: http://www.sciencelab.com/msds. php?msdsId=9923296. Accessed May 21, 2013.

11. Rollyson WD, Stover CA, Brown KC, et al. Bioavailability of capsaicin and its implications for drug delivery. J Control Release. 2014;196: 96-105.

12. Surh Y-J, Lee E, Lee JM. Chemopreventive properties of some pungent ingredients present in red pepper and ginger. Mutat Res. 1998;402: 259-267.

13. Yoshitani SI, Tanaka T, Kohno H, Takashima S. Chemoprevention of azoxymethane-induced rat colon carcinogenesis by dietary capsaicin and rotenone. Int J Oncol. 2001;19:929-939.

14. Sanchez AM, Malagarie-Cazenave S, Olea N, Vara D, Chiloeches A, Diaz-Laviada I. Apoptosis induced by capsaicin in prostate PC-3 cells involves ceramide accumulation, neutral sphingomyelinase, and JNK activation. Apoptosis. 2007;12:2013-2024.

15. Sanchez AM, Sanchez MG, Malagarie-Cazenave S, Olea N, DiazLaviada I. Induction of apoptosis in prostate tumor pc-3 cells and inhibition of xenograft prostate tumor growth by the vanilloid capsaicin. Apoptosis. 2006;11:89-99.

16. Henderson DE, Slickman AM, Henderson SK. Quantitative HPLC determination of the antioxidant activity of capsaicin on the formation of lipid hydroperoxides of linoleic acid: a comparative study against BHT and melatonin. J Agric Food Chem. 1999;47:2563-2570.

17. Kogure K, Goto S, Nishimura M, et al. Mechanism of potent antiperoxidative effect of capsaicin. Biochim Biophys Acta. 2002;1573: 84-92.

18. Okada Y, Okajima H. Antioxidant effect of capsaicin on lipid peroxidation in homogeneous solution, micelle dispersions and liposomal membranes. Redox Rep. 2001;6:117-122.

19. Materska M, Perucka I. Antioxidant activity of the main phenolic compounds isolated from hot pepper fruit (Capsicum annuum L.). J Agric Food Chem. 2005;53:1750-1756.

20. Dairam A, Fogel R, Daya S, Limson JL. Antioxidant and iron-binding properties of curcumin, capsaicin, and S-allylcysteine reduce oxidative stress in rat brain homogenate. J Agric Food Chem. 2008;56: 3350-3356.

21. Galano A, Martínez A. Capsaicin, a tasty free radical scavenger: mechanism of action and kinetics. J Phys Chem B. 2012;116: 1200-1208.

22. Luqman S, Rizvi SI. Protection of lipid peroxidation and carbonyl formation in proteins by capsaicin in human erythrocytes subjected to oxidative stress. Phytother Res. 2006;20:303-306.

23. De AK, Agarwal K, Mukherjee A, Sengupta D. Inhibition by capsaicin against cyclophosphamide-induced clastogenicity and DNA damage in mice. Mutat Res. 1995;335:253-258.

24. De AK, Ghosh JJ. Capsaicin pretreatment protects free radical induced rat lung damage on exposure to gaseous chemical irritants. Phytother Res. 1989;3:159-161.

25. Joe B, Lokesh R. Role of capsaicin, curcumin and dietary n-3 fatty acids in lowering the generation of reactive oxygen species in rat peritoneal macrophages. Biochim Biophys Acta. 1994;1224:255-263.

26. Jung M-Y, Kang H-J, Moon A. Capsaicin induced apoptosis in SK-Hep-1 hepatocarcinoma cells involves Bcl-2 down regulation and capase-3 activation. Cancer Lett. 2001;165:139-145.

27. Ito K, Nakazato T, Yamato K, et al. Induction of apoptosis in leukemic cells by homovanillic acid derivative, capsaicin, through oxidative stress: implication of phosphorylation of p53 at Ser-15 residue by reactive oxygen species. Cancer Res. 2004;64:1071-1078.

28. Perucka I, Materska M. Phenylalanine ammonia-lyase and antioxidant activities of lipophilic fraction of fresh pepper fruits Capsaicin annum L. Innov Food Sci Emerg Technol. 2001;2:189-192.

29. Schneider EL, Sternberg M, Tice RR. In vivo analysis of cellular replications. Proc Natl Acad Sci U S A. 1977;74:2041-2044.

30. De AK, Ghosh JJ. Inflammatory response of acute and chronic capsaicin treatment on rat paw. Phytother Res. 1988;2:175-179.
31. De AK, Ghosh JJ. Effects of short term capsaicin treatment on formalin and nitrogen dioxide induced changes in lipid peroxidation and antioxidant enzyme system in rat lung. Phytother Res. 1991;5:88-90.

32. De AK, Ghosh JJ. In vitro and in vivo studies on capsaicin and membrane bound calcium interactions in the rat lung using chlorotetracycline as a fluorescence probe. Phytother Res. 1991;5:5-8.

33. De AK, Ghosh JJ. Studies on capsaicin inhibition of chemical induced lipid peroxidation in the rat and liver tissues of rat. Phytother Res. 1992;6:34-37.

34. De AK, Ghosh JJ. Capsaicin action modulates lipid peroxidation induced by different irritants. Phytother Res. 1993;7:273-277.

35. De AK, Mandal TK, Ghosh JJ. Ultraviolet radiation induced lipid peroxidation in the liposomal membrane: modification by capsaicin. Phytother Res. 1993;7;87-89.

36. Ahuja KD, Kunde DA, Ball MJ, Geraghty DP. Effects of capsaicin, dihydrocapsaicin and curcumin on copper induced oxidation of human serum lipids. J Agric Food Chem. 2006;54:6436-6439.

37. Anandakumar P, Kamaraj S, Jagan S, et al. Capsaicin inhibits benzo(a) pyrene-induced lung carcinogenesis in an in vivo mouse model. Inflamm Res. 2012;61:1169-1175.

38. Anandakumar P, Kamaraj S, Ramakrishnan G, Jagan S, Devaki T. Chemopreventive task of capsaicin against benzo(a)pyrene-induced lung cancer in Swiss albino mice. Basic Clin Pharmacol Toxicol. 2009;104:360-365.

39. Surh Y-J, Lee SS. Capsaicin a double edged sword: toxicity, metabolism and chemopreventive potential. Life Sci. 1995;56:1845-1855.

40. Surh Y-J, Lee RC-J, Park K-K, Mayne ST, Liem A, Miller JA. Chemoprotective effects of capsaicin and diallyl sulfide against mutagenesis or tumorigenesis by vinyl carbamate and $\mathrm{N}$-nitrosodimethylamine. Carcinogenesis. 1995;16:2467-2471.

41. Devasagayam TP. Lipid peroxidation in rat uterus. Biochim Biophys Acta. 1986;876:507-514.

42. Lowry OH, Rosebrough NJ, Farr LA, Randal RJ. Protein measurement with the Folin phenol reagent. J Biol Chem. 1951;193:265-267.

43. Sinnhuber RO, Yu TC. 2-Thiobarbituric acid for the measurement of rancidity in fishery products II. The qualitative measurement of malondialdehyde. Food Technol. 1958;12:9-12.

44. Hunter FE, Gebicki JM, Hoffsten PE, Weinstein J, Scott A. Swelling and lysis of rat liver mitochondria induced by ferrous ions. J Biol Chem. 1963;238:828-835.

45. Jiang Z-Y, Hunt JV, Wolf SP. Ferrous ion oxidation in the presence of xylenol orange for detection of lipid hydroperoxide in low density lipoprotein. Anal Biochem. 1992;202:384-389.

46. Jocelyn PC. Spectrophotometric assay of thiols. Methods Enzymol. 1987;143:44-67.

47. Santos AC, Uyemura SA, Lopes JL, Bazon JN, Mingatto FE, Curti C. Effect of naturally occurring flavonoids on lipid peroxidation and membrane permeability transition in mitochondria. Free Radic Biol Med. 1998;24:1455-1461.

48. Palamanda JR, Kehrer JP. Inhibition of protein carbonyl formation and lipid peroxidation by glutathione in rat liver microsomes. Arch Biochem Biophys. 1992;293:103-109.

49. Sun M, Zigman S. An improved spectrophotometric assay for superoxide dismutase based on epinephrine autoxidation. Anal Biochem. 1978;90:81-89.

50. Caplan AI, Greenawalt JW. The effect of osmotic lysis on the oxidative phosphorylation and compartmentation of rat liver mitochondria. $J$ Cell Biol. 1968;36:15-31.

51. Cohn VH, Lyle J. A fluorometric assay for glutathione. Anal Biochem. 1966;14:434-440.

52. Hissin PJ, Hilf R. A fluorometric method for determination of oxidized and reduced glutathione in tissues. Anal Biochem. 1976;74: 214-226.

53. Guha SN, Moorthy PN, Kishore K, Naik DB, Rao KN. One-electron reduction of thionine studied by pulse radiolysis. Proc Indian Acad Sci (Chem Sci). 1987;99:261-271. 
54. Joshi R, Kamat JP, Mukherjee T. Free radical scavenging reactions and antioxidant activity of embelin: pulse radiolytic and biochemical studies. Chem Biol Interact. 2007;167:125-134.

55. Saravanon T, Khashid SS, Joshi R, Adhikari S, Mukherjee T. Free radicals induced oxidation of capsaicin: formation of benzylic and phenoxyl radicals. Indian J Radiat Res. 2004;1:113-122.

56. Ebbesen TW, Levey G, Patterson LK. Photoreduction of methyl viologen in aqueous neutral solution without additives. Nature. 1982;298:545-547.
57. Scott SL, Chen W-J, Bakac A, Espenson JH. Spectroscopic parameters, electrode-potentials, acid ionization constants, and electron exchange rates of the 2,2'-azinobis(3-ethylbenzothiazoine-6-sulfonate) radicals and ions. J Phys Chem. 1993;97:6710-6714.

58. Okada Y, Okajima H, Shima Y, Ohta H. Hydroxyl radical scavenging action of capsaicin. Redox Rep. 2002;7:153-157.

Research and Reports in Biochemistry

\section{Publish your work in this journal}

Research and Reports in Biochemistry is an international, peer-reviewed open access journal publishing original research, reports, reviews and commentaries on all areas of biochemistry. The manuscript management system is completely online and includes a very quick and fair peer-review system. Visit http://www.dovepress.com/testimonials.php to read real quotes from published authors. 